Published in final edited form as:

J Pediatr. 2010 June ; 156(6): 1023-1025. doi:10.1016/j.jpeds.2010.01.054.

\title{
Primary ciliary dyskinesia in Amish communities
}

\author{
Hauw Lie ${ }^{1}$, Maimoona A Zariwala ${ }^{5}$, Cynthia Helms ${ }^{2}$, Anne M Bowcock ${ }^{2}$, John L Carson ${ }^{4}$, \\ David E Brown III ${ }^{4}$, Milan J Hazucha ${ }^{5}$, James Forsen ${ }^{3}$, David Molter ${ }^{3}$, Michael R Knowles 6 , \\ Margaret W Leigh ${ }^{4}$, and Thomas W Ferkol ${ }^{1}$ \\ ${ }^{1}$ Department of Pediatrics, Washington University School of Medicine, St. Louis, Missouri \\ 2Department of Genetics, Washington University School of Medicine, St. Louis, Missouri \\ ${ }^{3}$ Department of Otolaryngology, Washington University School of Medicine, St. Louis, Missouri \\ ${ }^{4}$ Department of Pediatrics, University of North Carolina, Chapel Hill, North Carolina \\ ${ }^{5}$ Department of Pathology and Laboratory Medicine, University of North Carolina, Chapel Hill, North \\ Carolina \\ ${ }^{6}$ Department of Medicine, University of North Carolina, Chapel Hill, North Carolina
}

\begin{abstract}
Primary ciliary dyskinesia (PCD) is an autosomal recessive multigenic disease that results in impaired mucociliary clearance. We have diagnosed 9 subjects with primary ciliary dyskinesia from geographically dispersed Amish communities, based on clinical characteristics and ciliary ultrastructural defects. Despite consanguinity, affected individuals had evidence of genetic heterogeneity.
\end{abstract}

\section{Keywords}

Primary ciliary dyskinesia; cilia; dynein; nitric oxide; Amish

\begin{abstract}
Primary ciliary dyskinesia (PCD) is an inherited disorder characterized by functional impairment of ciliary motility, clinically manifested as chronic bronchitis, pansinusitis, and suppurative otitis media (1). Evidence of ciliary dysfunction can occur as early as birth with respiratory distress in the immediate newborn period (2). Ciliary dysfunction can lead to laterality defects, e.g. situs inversus totalis $(3,4)$. As predicted from the complexity of ciliary structure and function, PCD is genetically heterogeneous, involving multiple genes. In most instances, the disease is expressed in an autosomal recessive pattern
\end{abstract}

First settling in rural Pennsylvania, close-knit agrarian Amish communities have spread across North America. Because members rarely marry outside the church, consanguinity is common resulting in closed populations with a high frequency of genetic disorders. Intermarriage,

(C) 2009 Mosby, Inc. All rights reserved.

Corresponding author: Thomas Ferkol, MD, Division of Pediatric Allergy, Immunology, and Pulmonary Medicine, Department of Pediatrics, 660 South Euclid Avenue, Mailbox 8116, St. Louis, Missouri, 63110. Telephone: 314286 2886. Facsimile: 3144542515. ferkol_t@kids.wustl.edu.

Publisher's Disclaimer: This is a PDF file of an unedited manuscript that has been accepted for publication. As a service to our customers we are providing this early version of the manuscript. The manuscript will undergo copyediting, typesetting, and review of the resulting proof before it is published in its final citable form. Please note that during the production process errors may be discovered which could affect the content, and all legal disclaimers that apply to the journal pertain.

The authors declare no conflicts of interest. 
relative isolation, and detailed record-keeping make Amish communities ideal for genetic studies. We found that several children in geographically dispersed Amish communities had PCD, and hypothesized that additional evaluation would confirm a high frequency of PCD in these communities and identify a founder mutation.

\section{METHODS}

23 individuals from Amish communities in the Midwest who had respiratory distress as term infants in the immediate neonatal period, situs inversus totalis, recurrent pneumonia, chronic sinusitis, or male infertility were recruited at a one-day outreach clinic for further study. Signed informed consent was obtained from all subjects and family members.

Evaluations included detailed clinical and family histories, physical examination, and otolaryngological assessment. Nasal nitric oxide (NO) levels were measured using established techniques (model CLD 88, Eco Medics AG). Spirometry and audiometry were performed on subjects 5 years or older. Sputum or oropharyngeal swabs were collected for microbiological studies. Nasal scrapings from inferior nasal turbinates were obtained to collect ciliated epithelial cells for ultrastructural analysis. Blood or buccal cell samples were collected for genetic analysis; DNA was extracted using a commercially available DNA extraction kit. Whole genome amplification (REPLI-g kit, Qiagen) was performed on each sample to provide adequate genetic material for testing. Focused, mutational analysis and sequencing of DNAII was performed. Allele image profiles were generated using genotyping derived from 10K single nucleotide polymorphism arrays (Affimetrix) and microsatellite markers, short DNA segments with repeated, specific motifs 1-6 bases long, for candidate genes (DNAII, DNAH5, DNAH11, DNAH7, DNAH9, DNAI2, DNAL4, DNAH3, and TCTEL1). Haplotypes were reconstructed such that genotypes could be visualized on pedigrees, and homozygosity mapping was used to identify a common genetic locus in the consanguineous family.

\section{RESULTS}

15 males and 8 females from infancy to adulthood (age range 3 months to 45 years) underwent evaluation. Based on ciliary ultrastructural analysis, 9 of the subjects (6 male) evaluated were confirmed to have dynein arm defects (absence of outer dynein arm) consistent with PCD. Subjects with PCD ranged in age from 3 months to 40 years (median age 14 years).

All were born at term, and 8 cases had neonatal respiratory distress (8/9). Every affected individual had persistent nasal congestion and coughing. Other clinical findings included laterality defects (5/9), chronic rhinosinusitis (8/9), and pneumonia (5/9). Surprisingly, only one subject (1/9) had a history of recurrent, symptomatic acute otitis media. However, audiological evaluations performed on 5 older children and adults revealed mildly or moderately abnormal tympanometry measurements and conductive hearing loss thought to be due to otitis media with effusion.

In the 4 subjects with PCD who could perform spirometry, the mean FVC was $74.5 \%$ (range 55 to $82 \%$ ) and mean FEV1 was $66.5 \%$ predicted for age (range 36 to $80 \%$ ). Bacterial pathogens isolated from sputum cultures included Haemophilus influenzae (6/9), Streptococcus pneumoniae (2/9), and Pseudomonas aeruginosa (1/9). Atypical mycobacteria were isolated from an adult PCD subject (1/9).

Nasal NO measurements were extremely low in these subjects ranging from 1.2 to $11.1 \mathrm{~nL} /$ min with all 9 PCD subjects having NO levels $<14 \mathrm{~nL} / \mathrm{min}$.

Initial genetic testing from those with confirmed PCD at selected exons identified 3 individuals carrying a founder splice mutation (IVS1+2_3insT) of DNAIl, the most common mutation 
associated with PCD (Figure). This mutation was present on a single allele, and full sequencing of DNAII in these subjects did not reveal a second mutation. Genotype analysis of selected microsatellites from candidate genes followed Mendelian patterns of inheritance, based on haplotypes. No concordance was found in affected individuals within the same family with any microsatellite marker tested, indicating that affected individuals harbor a disease-causing mutation in a previously unidentified PCD gene. Genome-wide linkage search of closely related PCD subjects was performed, and multipoint linkage analysis identified 4 regions of high concordance on chromosomes $2 \mathrm{p}, 4 \mathrm{p}, 6 \mathrm{p}$, and 13p.

\section{DISCUSSION}

We describe members from related Amish communities who have PCD, based on clinical evaluation and ultrastructural defects of the ciliary axoneme. Extensive, genetic analyses, however, indicated significant genetic heterogeneity.

PCD has been estimated to occur in approximately 1 in 12,000 to 20,000 live births $(3,4)$. The current "gold standard" for diagnosis relies on identification of ciliary ultrastructural abnormalities by transmission electron microscopy (5), but this method has drawbacks (6). Fuller understanding of the genetic basis of PCD may lead to another, superior diagnostic modality to identify affected individuals. The genetic heterogeneity of PCD is predicted by the complexity of the ciliary structure (7). Several potential candidate dynein genes are involved in PCD, including mutations in DNAII (8) and DNAH5 (9). Other dynein arm-coding genes, $D N A H 11$ and $D N A H 7$, have also been associated with PCD (10).

All subjects in this population with confirmed PCD reported chronic nasal congestion and cough. Although there are other causes of neonatal respiratory distress, our population supports the observation that neonatal respiratory distress is a common presenting feature of PCD. Surprisingly, only one subject had a history of chronic middle ear involvement, a feature thought to be common to all PCD patients. The reason for the low prevalence of otitis media in this population is unclear, though it is likely related in part to underreporting.

Spirometry revealed significant intrathoracic airway obstruction in subjects who could perform pulmonary function testing, though it is difficult to make conclusions based on the few subjects studied. Nasal NO concentrations were low in all subjects with PCD, confirming previous observations that individuals with PCD typically have reduced nasal NO production (10).

In conclusion, we have found that several members of related, geographically dispersed, Amish families have PCD. Although the specific genetic causes for most PCD are still unknown, such families provide us with an opportunity to understand this "rare" lung disease. We have collected extensive clinical and family data describing affected individuals, which should allow us to better define the genetics of disease and phenotype-genotype relationships. Already, we have found unexpected genetic heterogeneity in this inbred Amish community. Further evaluation is necessary to identify the specific mutations in this population.

\section{Acknowledgments}

The authors would like to thank Jane Quante, Susan Minnix, and Kimberly Burns for their expert assistance on the project. We also appreciate the efforts of Katherine Rivera, Lila Kertz, Kristina Shilts, Carolyn Cannon, John Spivey, and Deborah White, who participated in the outreach clinic.

Supported by National Institutes of Health awards RR019480 (M.R.K.), HL071798 (M.R.K.), and HL079024 (T.W.F.), and the Children's Discovery Institute (T.W.F.). 


\section{ABBREVIATIONS}

NO nitric oxide

PCD primary ciliary dyskinesia

DNAII dynein axonemal intermediate chain 1

\section{REFERENCES}

1. Knowles MR, Boucher RC. Mucus clearance as a primary innate defense mechanism for mammalian airways. J Clin Invest 2002;209:571-577. [PubMed: 11877463]

2. Noone PG, Leigh MW, Sannuti A, Minnix SL, Carson JL, Hazucha M, Zariwala MA, Knowles MR. Primary ciliary dyskinesia: diagnostic and phenotypic features. Am J Respir Crit Care Med 2004;169:459-467. [PubMed: 14656747]

3. Torgersen J. Situs inversus, asymmetry, and twinning. Am J Hum Genet 1950;2:361-370. [PubMed: 14837905]

4. Katsuhara K, Kawamoto S, Wakahayashi T, et al. Situs inversus totalis and Kartagener's syndrome in a Japanese population. Chest 1972;61:56-61. [PubMed: 4538074]

5. Bush A, Chodhari R, Collins N, Copeland F, Hall P, Harcourt J, Hariri M, Hogg C, Lucas J, Mitchison HM, O'Callaghan C, Phillips G. Primary ciliary dyskinesia: current state of the art. Arch Dis Child 2007;92:1136-1140. [PubMed: 17634184]

6. Ferkol T, Leigh M. Primary ciliary dyskinesia and newborn respiratory distress. Semin Perinatol 2006;30:335-340. [PubMed: 17142159]

7. Dutcher SK. Flagellar assembly in two hundred and fifty easy-to-follow steps. Trends Genet 1995;11:398-404. [PubMed: 7482766]

8. Zariwala MA, Leigh MW, Ceppa F, Kennedy MP, Noone PG, Carson JL, Hazucha MJ, Lori A, Horvath J, Olbrich H, Loges NT, Bridoux AM, Pennarun G, Duriez B, Escudier E, Mitchison HM, Chodhari R, Chung EM, Morgan LC, de Iongh RU, Rutland J, Pradal U, Omran H, Amselem S, Knowles MR. Mutations of DNAII in primary ciliary dyskinesia: evidence of founder effect in a common mutation. Am J Respir Crit Care Med 2006;174:858-866. [PubMed: 16858015]

9. Hornef N, Olbrich H, Horvath J, Zariwala MA, Fliegauf M, Loges NT, Wildhaber J, Noone PG, Kennedy M, Antonarakis SE, Blouin JL, Bartoloni L, Nusslein T, Ahrens P, Griese M, Kuhl H, Sudbrak R, Knowles MR, Reinhardt R, Omran H. DNAH5 mutations are a common cause of primary ciliary dyskinesia with outer dynein arm defects. Am J Respir Crit Care Med 2006;174:120-126. [PubMed: 16627867]

10. Leigh MW, Pittman JE, Carson JL, Ferkol TW, Dell SD, Davis SD, Knowles MR, Zariwala MA. Clinical and genetic aspects of primary ciliary dyskinesia/Kartagener syndrome. Genet Med 2009;11:473-487. [PubMed: 19606528] 


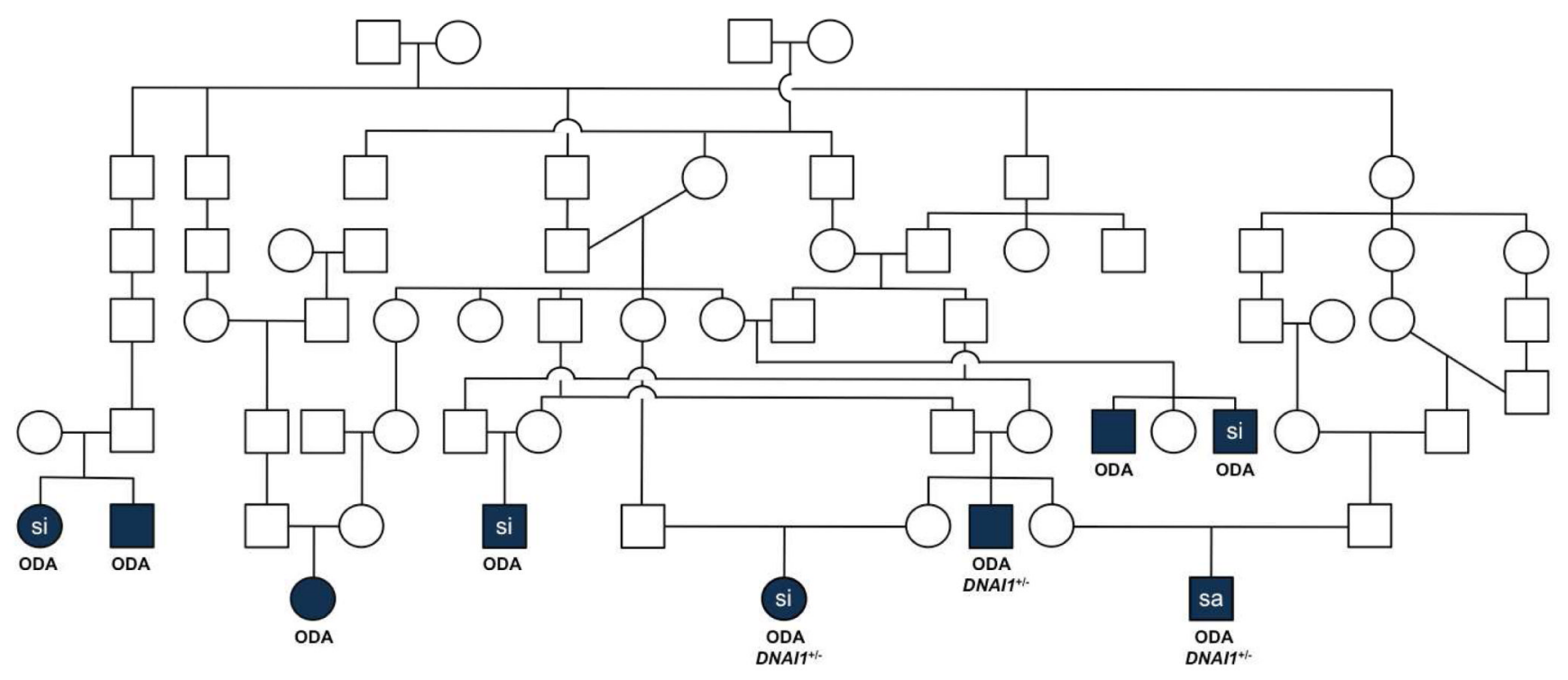

Figure.

Pedigree of consanguineous kindred with related nuclear families. Legend: si, situs inversus; sa, situs ambiguus; ODA, outer dynein arm defect; DNAII, dynein axonemal intermediate chain $1 ;+/-$, heterozygous. Symbols: $\square$ male, $\circ$ female, and filled symbols indicate affected individuals. Three subjects with confirmed PCD carried a splice mutation (IVS1+2_3insT) of $D N A I 1$, and the other 6 affected individuals were negative for this founder mutation. 